\title{
Canales de noticias en el Perú. Analizando la información y la investigación
}

\author{
Recibido: 02 de noviembre de 2015 \\ Aceptado: 17 de junio de 2016 \\ Publicado: 30 de noviembre de 2016
}

\author{
Pablo Macalupú Cumpén \\ macalupu.pablo@gmail.com \\ Universidad de San Martín de Porres (Perú)
}

Resumen: Los canales de noticias en el Perú existen desde finales de los noventas. La creación de espacios temáticos dedicados a la información continua surgió como una necesidad de mantener informada a una población que, hasta ese entonces, sólo recibía enfoques parciales producto de negociaciones de Fujimori-Montesinos con algunos dueños de medios de comunicación de señal abierta. Canal $N$ fue el segundo canal de noticias por cable aparecido en el Perú y fundado en 1999 (el primero fue Cable Canal de Noticias y, al igual que varios de señal abierta, también negoció con Montesinos). Esta estación fue la única en su tiempo en presentar a su audiencia información independiente y balanceada. A partir de 2010, once años después, surgen otros canales como Willax TV, $A T V+$ Noticias, RPP TV y TV Perú 7.3. Recientemente, Capital TV y Exitosa han aparecido como una alternativa para presentar sus programas radiales de una forma audiovisual. En consecuencia, esta diversidad editorial nos invita a analizar en detalle sus enfoques y contenidos. En este artículo, revisaremos la cobertura de la captura de Rodolfo Orellana y la denuncia sobre el resguardo policial irregular en la casa de Óscar López Meneses, un personaje vinculado a Vladimiro Montesinos.

Palabras clave: Periodismo, televisión, canales de noticias, canales temáticos, contenidos de televisión.

Abstract: TVNews Channels in Peru exists since late nineties. This kind of media appeared
as a public necessity because, in that moment, news coverage was coming from TV stations
that negotiated its editorial terms with Fujimori and Montesinos. The second TV News
Channel in Peru was Canal N (the first-Cable Canal de Noticias-also had negotiated with 
Montesinos). This TV station was founded in 1999 and was the only one that presented balanced and impartial approaches to their audience in that time on TV. Since 2010, other channels have emerged, such as Willax TV, ATV+ Noticias, RPP TV and TV Perú 7.3. Recently, Capital TV and Exitosa appeared as an alternative space to present their radio news programmes but in an audiovisual format. Therefore this editorial diversity invites us to analyse in detail their approaches and contents. In this article, we will review the coverage of Rodolfo Orellana capture and the report about Óscar López Meneses' irregular police safeguard, a man linked to Vladimiro Montesinos.

Key words: Journalism, Television, News Channels, Thematic Channels, TV Contents.

\section{Televisión especializada}

La industria de los canales de noticias en el mundo está cerca de cumplir cuarenta años. Uno de los pioneros en esta categoría es $C N N$, el primero en ofrecer información las 24 horas al día, una característica que en sus inicios parecía una locura, pero cuyo modelo se replica hoy en casi todos los países de los cinco continentes. De hecho, las numerosas sedes del mismo $C N N$ en el mundo son una muestra de ello. Se puede mencionar otras estaciones y experiencias como la $B B C$ World News, en el Reino Unido, con competidores como Sky News UK; Al Jazeera y Al Arabiya, principales medios noticiosos en Medio Oriente; NTN24 y TeleSUR en Latinoamérica, entre otros.

A diferencia de los medios de entretenimiento, los canales de noticias tienen un alto impacto en la sociedad y las altas esferas del poder. Como ejemplo de ello se puede mencionar casos concretos como la censura contra NTN24, realizada por el gobierno del Nicolás Maduro en Venezuela, en febrero de 2014 (El Universal, 2014), o la cobertura de la "revolución árabe" realizada por Al Jazeera, cuestionada por muchos rivales del medio y los países del Golfo debido a sus vínculos con el gobierno catarí.

En los noventas, el Perú no fue ajeno a las tendencias mediáticas. De acuerdo con Hume (2014), en 1997 se propuso a Telefónica un canal de noticias de bajo costo, aprovechando el sistema digital que en aquel entonces estaba desarrollándose. El propósito era emitir los procesos del Poder Judicial por la mañana y transmisiones del Pleno del Congreso por la tarde. Este proyecto fue trabajado junto con Tomás D’Ornellas y Ricardo Ghibellini, pero fue rechazado para evitar "problemas por cuestiones políticas, aunque les gustaba la idea de un canal del Congreso". Tiempo después, Hume conversó de esta idea con Bernardo Roca Rey y es así como El Comercio incluye el proyecto a su gerencia de nuevos negocios que entonces trabajaba productos como Trome y Perú21. De esta manera, surge Canal $N$ un 4 de julio de 1999. El año anterior había salido al aire Cable Canal de Noticias, un producto del diario Expreso que dejó de operar en 2001 luego de que se descubriera que fue un medio más (de los varios) que había comprado Vladimiro Montesinos.

La salida al aire de Canal $N$ tuvo un impacto similar al de los casos extranjeros citados en párrafos anteriores, sobre todo enmarcado en el proceso electoral de 1999-2000. Es 
importante agregar que fue el canal que transmitió el primer "vladivideo" en el que se ve al ex asesor presidencial sobornando a un congresista opositor para pasarse a sus filas. Desde el 2010 en adelante surgieron nuevas iniciativas independientes. Tales son los casos de Willax $T V$ (canal fundado por el mismo Gilberto Hume) y que ahora ha cambiado su programación de "todo noticias" a generalista; $R P P T V$, lanzado en enero de $2011 \mathrm{y}$ perteneciente al Grupo RPP; ATV + Noticias, fundado también en 2011 por el Grupo ATV; y $T V$ Perú 7.3, la señal informativa del canal del Estado, TV Perú, administrada por el Instituto Nacional de Radio y Televisión.

En el Perú también existen otros canales de noticias y medios informativos especializados como Capital TV (del Grupo RPP), el canal del Congreso, Cable Mágico Deportes (CMD), canal del hipódromo de Monterrico y Exitosa. Algunos de estos están dedicados a temáticas específicas (deportes, hípica, política) y otros varían por su enfoque (análisis y opinión).

\section{La investigación}

El propósito del artículo es comparar el tratamiento informativo otorgado a la captura de Rodolfo Orellana (13/XI/2014), bajo la sospecha de ser "el cabecilla de una red de estafa y lavado de activos que logró amasar unos US\$ 100 millones" (El Comercio, 2014) por parte de los cinco principales canales de noticias de ese entonces: Canal N, Willax TV, $A T V+$ Noticias, RPP TV y TV Perú 7.3. Asimismo, se escogió un reportaje de investigación realizado en noviembre de 2013 por Willax $T V$ sobre el resguardo policial a la casa de Óscar López Meneses, que produjo un gran impacto político, así como renuncias de funcionarios y pesquisas ulteriores.

El presente estudio toma en consideración los elementos de análisis comparativo propuestos por Bandrés y otros (2000: 288 y 289).

\section{Un tema, cinco puntos de vista}

El tópico elegido fue la captura de Rodolfo Orellana. Como muestra de análisis, se tomaron al azar sólo algunas de las informaciones aparecidas sobre este caso (figuras 1-5). Es importante señalar que este hecho fue cubierto por todos los canales de noticias desde la mañana del 13 de noviembre (momento de su captura) pero cada uno con su propio estilo, con entrevistas para conocer las reacciones de los políticos sobre el hecho, informes sobre quién era Rodolfo Orellana, entre otros recursos aprovechados por los medios televisivos. 
Figura 1: Análisis de nota informativa aparecida en "Primero a las 8", de Canal N.

\begin{tabular}{|c|c|}
\hline \multicolumn{2}{|r|}{ DATOS GENERALES } \\
\hline $\begin{array}{l}\text { Fecha de emisión } \\
\text { del informativo }\end{array}$ & 13 de noviembre de 2014 . \\
\hline Tema de la noticia & Captura de Rodolfo Orellana. \\
\hline $\begin{array}{l}\text { Lugar que ocupa } \\
\text { en el informativo }\end{array}$ & Primer bloque. Inicio del noticiero del prime time de Canal $N$. \\
\hline Texto de la noticia & 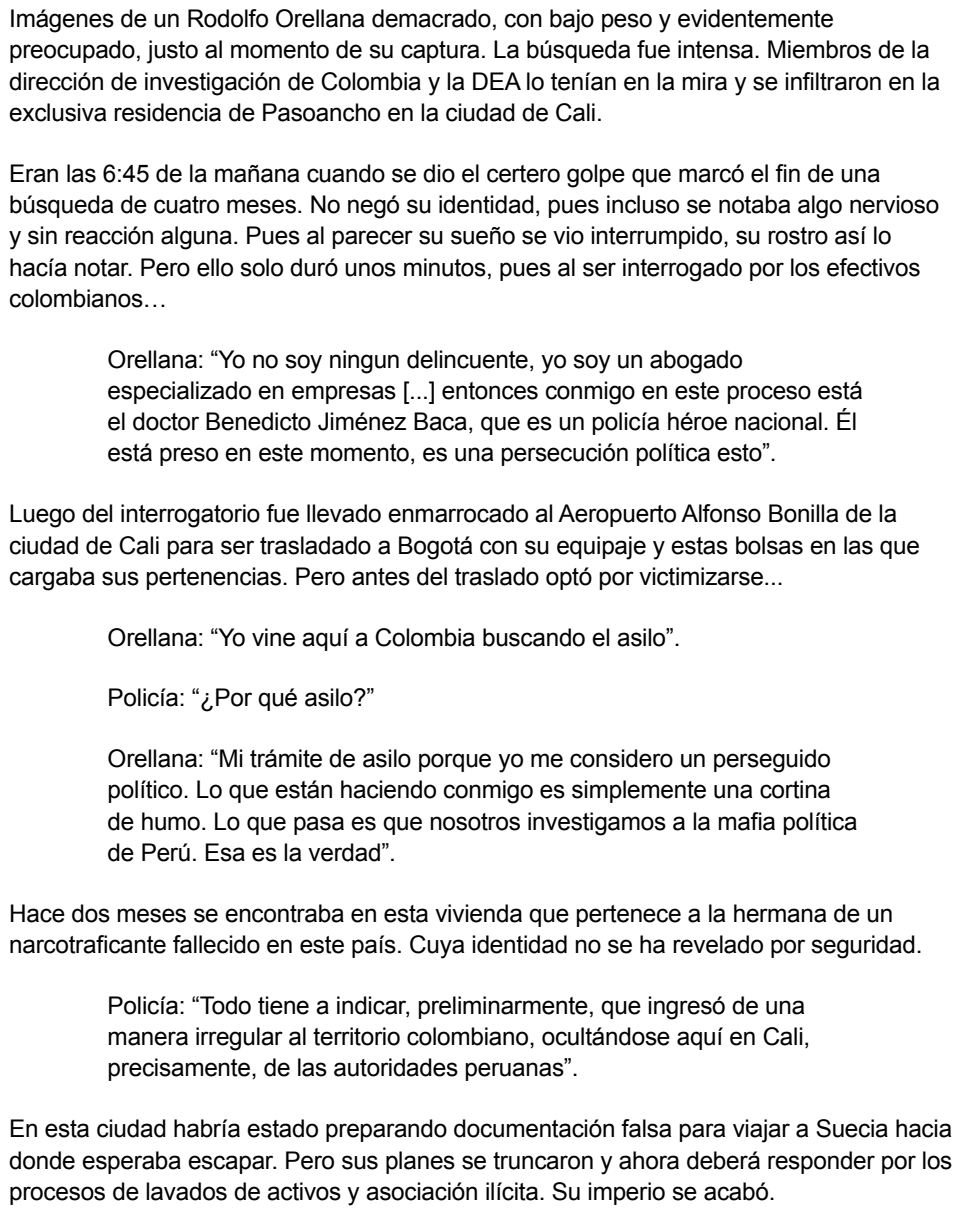 \\
\hline $\begin{array}{l}\text { Duración de la } \\
\text { noticia }\end{array}$ & 2' 44". \\
\hline
\end{tabular}




\section{ESTRUCTURA DE LA NOTA INFORMATIVA}

\begin{tabular}{|c|c|c|}
\hline \multirow{2}{*}{$\begin{array}{l}\text { Esta es una } \\
\text { noticia narrada } \\
\text { cronológicamente } \\
\text { desde la captura de } \\
\text { Rodolfo Orellana } \\
\text { hasta los momentos } \\
\text { previos a su } \\
\text { traslado a Bogotá. } \\
\text { Se componen } \\
\text { frases cortas. }\end{array}$} & $\begin{array}{l}\text { Las primeras imágenes son del rostro de } \\
\text { Rodolfo Orellana al momento de su captura. Se } \\
\text { describe el estado físico y anímico del detenido. } \\
\text { A continuación, se detalla quiénes fueron los } \\
\text { captores, dónde se realizó el operativo y en qué } \\
\text { momento. } \\
\text { Luego se vuelve a tratar directamente } \\
\text { al personaje y su actitud tras la captura, } \\
\text { presentándose la primera declaración de } \\
\text { Orellana. Terminado el soundbite, el informe } \\
\text { continúa con el traslado de Orellana al Bogotá. } \\
\text { En ese momento se presenta un nuevo extracto } \\
\text { de lo que le dijo a los policías. }\end{array}$ & 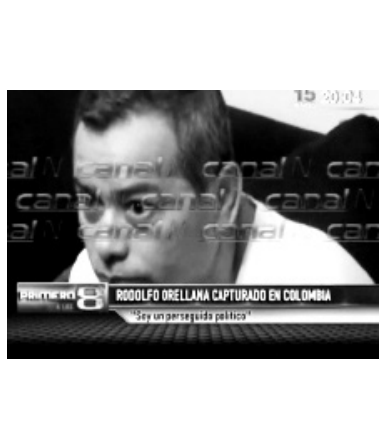 \\
\hline & $\begin{array}{l}\text { Finalmente, se ofrecen los detalles como la } \\
\text { cantidad de tiempo que estuvo escondido de la } \\
\text { justicia en la casa donde fue encontrado, a quien } \\
\text { pertenecía la vivienda, cómo es que ingresó a } \\
\text { Colombia y cuáles eran los pasos que pensaba } \\
\text { seguir para escapar. }\end{array}$ & 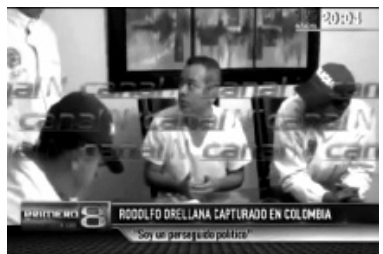 \\
\hline \multicolumn{3}{|c|}{ COMPOSICIÓN } \\
\hline $\begin{array}{l}\text { Número de planos } \\
\text { en la noticia }\end{array}$ & \multicolumn{2}{|c|}{$\begin{array}{l}\text { Esta noticia incluye alrededor de } 18 \text { planos. La duración mínima es de } 2 \text { segundos y la } \\
\text { máxima de } 30 \text { segundos por plano. }\end{array}$} \\
\hline $\begin{array}{l}\text { Escenarios que } \\
\text { aparecen en la } \\
\text { noticia }\end{array}$ & \multicolumn{2}{|c|}{$\begin{array}{l}\text { Cuatro momentos distintos: el interior de la casa donde estaba Orellana, exterior de la } \\
\text { casa, local policial de donde se recoge la declaración de un agente y base aérea de } \\
\text { donde sale Orellana hacia Bogotá. }\end{array}$} \\
\hline $\begin{array}{l}\text { Tipos de planos } \\
\text { y relación con el } \\
\text { texto }\end{array}$ & \multicolumn{2}{|c|}{$\begin{array}{l}\text { Este informe cuenta con planos generales, primeros planos (de Orellana), planos } \\
\text { medios (y medios cortos) y planos secuencia (en la toma de mayor duración que se } \\
\text { incluye en el informe). Sí hay relación entre las imágenes. }\end{array}$} \\
\hline \multicolumn{3}{|c|}{ EDICIÓN } \\
\hline $\begin{array}{l}\text { Tipo de } \\
\text { transiciones } \\
\text { utilizadas }\end{array}$ & \multicolumn{2}{|l|}{ Se usa, principalmente, la disolvencia. } \\
\hline $\begin{array}{l}\text { Adecuación del } \\
\text { ritmo narrativo }\end{array}$ & \multicolumn{2}{|c|}{ Las imágenes se adecuan y concuerdan con el texto y le dan un ritmo a la noticia. } \\
\hline $\begin{array}{l}\text { Uso del sonido } \\
\text { ambiente }\end{array}$ & \multicolumn{2}{|c|}{$\begin{array}{l}\text { Se aprovechan los sonidos ambientales, sobre todo en el plano secuencia del momento } \\
\text { en que la Policía está buscando dentro de la casa a Orellana. }\end{array}$} \\
\hline $\begin{array}{l}\text { Relación entre el } \\
\text { texto y la imagen }\end{array}$ & \multicolumn{2}{|c|}{$\begin{array}{l}\text { Hay relación entre el texto y la imagen. Es mucho más notorio en casos específicos } \\
\text { como la descripción del rostro del capturado, el equipaje que llevaba o la casa en la que } \\
\text { se alojaba. }\end{array}$} \\
\hline $\begin{array}{l}\text { Riqueza visual } \\
\text { o escasez de } \\
\text { recursos }\end{array}$ & \multicolumn{2}{|c|}{$\begin{array}{l}\text { Se utilizan imágenes proporcionadas por la Policía de Colombia. Se puede notar que } \\
\text { se repiten dos planos: el detalle del rostro de Orellana y el de los agentes policiales } \\
\text { ingresando a la casa. }\end{array}$} \\
\hline
\end{tabular}




\begin{tabular}{|c|c|}
\hline \multicolumn{2}{|r|}{ LOCUCIÓN } \\
\hline $\begin{array}{l}\text { Tipo de voz y } \\
\text { dicción }\end{array}$ & $\begin{array}{l}\text { Voz femenina. En los inicios de frases predomina la parte aguda y desciende por lo } \\
\text { menos hasta un registro medio, pero nunca bajo. Dicción adecuada. }\end{array}$ \\
\hline $\begin{array}{l}\text { Tiempo verbal } \\
\text { usado en la } \\
\text { narración }\end{array}$ & La narración está en tiempo pasado. \\
\hline $\begin{array}{l}\text { Ritmo y fluidez en } \\
\text { la locución }\end{array}$ & $\begin{array}{l}\text { El ritmo es ágil, fluido y pausado al punto que se deja entender claramente todo el } \\
\text { contenido del texto. Ayuda también la edición. }\end{array}$ \\
\hline $\begin{array}{l}\text { Presencia del } \\
\text { periodista en } \\
\text { cámara }\end{array}$ & No hay. \\
\hline \multicolumn{2}{|l|}{ CONTENIDO } \\
\hline Fuentes utilizadas & $\begin{array}{l}\text { Se utiliza como fuente principal de información las imágenes de la Policía de Colombia, } \\
\text { así como el testimonio de uno de ellos. }\end{array}$ \\
\hline $\begin{array}{l}\text { Procedencia de } \\
\text { las imágenes }\end{array}$ & Policía de Colombia. \\
\hline $\begin{array}{l}\text { Estilo de la } \\
\text { redacción del } \\
\text { texto }\end{array}$ & $\begin{array}{l}\text { Es una nota cronológica de la captura hasta los instantes previos a su traslado a } \\
\text { Bogotá. }\end{array}$ \\
\hline $\begin{array}{l}\text { Valoraciones o } \\
\text { juicios de opinión }\end{array}$ & En una parte del texto se dice que Orellana se hizo "la víctima". \\
\hline Enfoque adoptado & $\begin{array}{l}\text { Esta noticia está enfocada principalmente a resaltar la captura y las reacciones de } \\
\text { Rodolfo Orellana tras su detención en Cali, Colombia. }\end{array}$ \\
\hline
\end{tabular}

Fuente: Elaboración propia, basada en YouTube (2014d).

Figura 2: Análisis de nota informativa aparecida en $R P P T V$.

\begin{tabular}{|l|l|}
\hline \multicolumn{2}{|c|}{ DATOS GENERALES } \\
\hline $\begin{array}{l}\text { Fecha de emisión del } \\
\text { informativo }\end{array}$ & 13 de noviembre de 2014. \\
\hline Tema de la noticia & Principales denuncias y cantidad de dinero manejado por Rodolfo Orellana. \\
\hline
\end{tabular}




\begin{tabular}{|c|c|c|}
\hline Texto de la noticia & \multicolumn{2}{|c|}{$\begin{array}{l}\text { Acusado de encabezar una organización criminal, Rodolfo Orellana amasó una } \\
\text { fortuna de más de } 100 \text { millones de dólares, gracias a la apropiación de inmuebles } \\
\text { de terceros, a través de diversas modalidades ilícitas. } \\
\text { La red Orellana registra más de } 400 \text { denuncias penales, nada menos que por } \\
\text { estafa, apropiación ilícita para delinquir, tráfico ilícito de drogas y lavado de } \\
\text { activos. Uno de los primeros agraviados en advertirlo fue el empresario Giovanni } \\
\text { Paredes, quien por maniobras judiciales de Orellana fue encarcelado siete meses } \\
\text { y perdió posesión del camal de Yerbateros. } \\
\text { Así comienza una extensa lista de víctimas que abarcan a instituciones como } \\
\text { el Ministerio de Educación y la Municipalidad de La Victoria. Todos atrapados } \\
\text { en una telaraña que fabrica falsos procesos arbitrales y embauca a entidades } \\
\text { bancarias con millonarios procesos hipotecarios. Y, por último, la COOPEX, una } \\
\text { cooperativa controlada por Orellana, creada para garantizar ante el Estado la } \\
\text { solvencia de empresas fantasma. } \\
\text { Uno de sus principales socios es el detenido ex coronel de la policía Benedicto } \\
\text { Jiménez. Juntos se dedicaron a amedrentar a cada autoridad y a cada periodista } \\
\text { que investigaba los ilícitos trabajos de esta organización. Delgado y demacrado. } \\
\text { Con este nuevo, rostro Rodolfo Orellana tendrá que afrontar ahora todas estas } \\
\text { irregularidades tras las rejas. }\end{array}$} \\
\hline Duración de la noticia & 1' 30 ". & \\
\hline \multicolumn{3}{|c|}{ ESTRUCTURA DE LA NOTA INFORMATIVA } \\
\hline \multicolumn{3}{|c|}{$\begin{array}{l}\text { Se hace un recuento de las acusaciones contra Rodolfo Orellana, el } \\
\text { dinero que habría movido la organización que lideraba, así como sus } \\
\text { principales agraviados y socios. Remata el informe con el personaje } \\
\text { ahora capturado. } \\
\text { En ese sentido, se presentan imágenes de archivo con un Rodolfo } \\
\text { Orellana libre y mediático. A continuación, las imágenes de sus víctimas } \\
\text { y casos específicos. El informe termina con él y su socio Benedicto } \\
\text { Jiménez capturados. }\end{array}$} \\
\hline \multicolumn{3}{|c|}{ COMPOSICIÓN } \\
\hline $\begin{array}{l}\text { Número de planos en la } \\
\text { noticia }\end{array}$ & \multicolumn{2}{|c|}{$\begin{array}{l}\text { Esta noticia incluye un total de } 36 \text { planos. La duración máxima es de } 5 \text { segundos } \\
\text { y la mínima de } 1 \text { segundo. }\end{array}$} \\
\hline $\begin{array}{l}\text { Escenarios que } \\
\text { aparecen en la noticia }\end{array}$ & \multicolumn{2}{|c|}{$\begin{array}{l}\text { Aproximadamente aparecen } 26 \text { momentos y lugares distintos en este background } \\
\text { del caso Rodolfo Orellana. }\end{array}$} \\
\hline $\begin{array}{l}\text { Tipos de planos y } \\
\text { relación con el texto }\end{array}$ & \multicolumn{2}{|c|}{$\begin{array}{l}\text { El material es rico en imágenes. Se pueden encontrar planos detalle, generales, } \\
\text { medios, planos secuencia, entre otros. }\end{array}$} \\
\hline \multicolumn{3}{|c|}{ EDICIÓN } \\
\hline $\begin{array}{l}\text { Tipo de transiciones } \\
\text { utilizadas }\end{array}$ & \multicolumn{2}{|l|}{ Se usa corte, disolvencias y pases a negro. } \\
\hline $\begin{array}{l}\text { Adecuación del ritmo } \\
\text { narrativo }\end{array}$ & \multicolumn{2}{|c|}{ Es rítmica y descriptiva de acuerdo con el texto. } \\
\hline Uso del sonido ambiente & \multicolumn{2}{|l|}{ No hay sonidos ambientales. } \\
\hline
\end{tabular}




\begin{tabular}{|c|c|}
\hline $\begin{array}{l}\text { Relación entre el texto y } \\
\text { la imagen }\end{array}$ & Durante la mayor parte del informe sí existe concordancia entre imagen y texto. \\
\hline $\begin{array}{l}\text { Riqueza visual o } \\
\text { escasez de recursos }\end{array}$ & $\begin{array}{l}\text { Esta noticia es muy rica en imágenes para la duración que tiene. Se han } \\
\text { aprovechado los recursos de archivo. Al hacerse referencia a Orellana, se usan } \\
\text { principalmente dos imágenes: Orellana hablando por teléfono y otra en el estudio de } \\
R P P \text {. }\end{array}$ \\
\hline \multicolumn{2}{|r|}{ LOCUCIÓN } \\
\hline Tipo de voz y dicción & Voz masculina. Manejo predominante del registro central. Dicción correcta. \\
\hline $\begin{array}{l}\text { Tiempo verbal usado en } \\
\text { la narración }\end{array}$ & $\begin{array}{l}\text { Cuando se trata de las acciones cometidas por Orellana se usa el tiempo pasado. } \\
\text { Al abordarse las acusaciones, el tiempo presente; y cuando se menciona la } \\
\text { captura se usa el futuro para decir que "tendrá que afrontar las irregularidades } \\
\text { tras las rejas". }\end{array}$ \\
\hline $\begin{array}{l}\text { Ritmo y fluidez en la } \\
\text { locución }\end{array}$ & Fluido, pero en tiempo moderado. \\
\hline $\begin{array}{l}\text { Presencia del periodista } \\
\text { en cámara }\end{array}$ & No hay. \\
\hline \multicolumn{2}{|r|}{ CONTENIDO } \\
\hline Fuentes utilizadas & $\begin{array}{l}\text { Como fuente para el contenido se utilizan los casos en los que estaba implicado Orellana } \\
\text { y se cita directamente a Giovanni Paredes, como una de sus principales víctimas. }\end{array}$ \\
\hline $\begin{array}{l}\text { Procedencia de las } \\
\text { imágenes }\end{array}$ & Archivo de RPP. \\
\hline $\begin{array}{l}\text { Estilo de la redacción } \\
\text { del texto }\end{array}$ & $\begin{array}{l}\text { Se maneja un estilo de recuento de las acciones cometidas por Rodolfo Orellana. } \\
\text { Resumen concreto y detallado de lo que hizo el acusado. }\end{array}$ \\
\hline $\begin{array}{l}\text { Valoraciones o juicios } \\
\text { de opinión }\end{array}$ & Su contenido se limita a brindar información. \\
\hline Enfoque adoptado & $\begin{array}{l}\text { El enfoque principal reside en detallar quién era, cómo era y qué hacía la } \\
\text { organización liderada por Rodolfo Orellana. }\end{array}$ \\
\hline
\end{tabular}

Fuente: Elaboración propia, basada en YouTube (2014f).

Figura 3: Análisis de alerta informativa emitida en $A T V+$.

\begin{tabular}{|l|l|}
\hline \multicolumn{2}{|c|}{ DATOS GENERALES } \\
\hline $\begin{array}{l}\text { Fecha de emisión del } \\
\text { informativo }\end{array}$ & 13 de noviembre de 2014. \\
\hline Tema de la noticia & Confirman deportación de Rodolfo Orellana Rengifo. \\
\hline $\begin{array}{l}\text { Texto de la entradilla } \\
\text { en estudio }\end{array}$ & $\begin{array}{l}\text { Bien tenemos ahora otra "Alerta +" siempre sobre este caso que ha concitado la } \\
\text { atención no solamente de la prensa nacional, sino colombiana e internacional, y } \\
\text { ahora nos vamos a enlazar con nuestro compañero, el periodista Carlos Gutiérrez } \\
\text { reportero de nuestro canal aliado Caracol. Carlos, buenos días... }\end{array}$ \\
\hline Duración de la noticia & 8' 33". \\
\hline
\end{tabular}




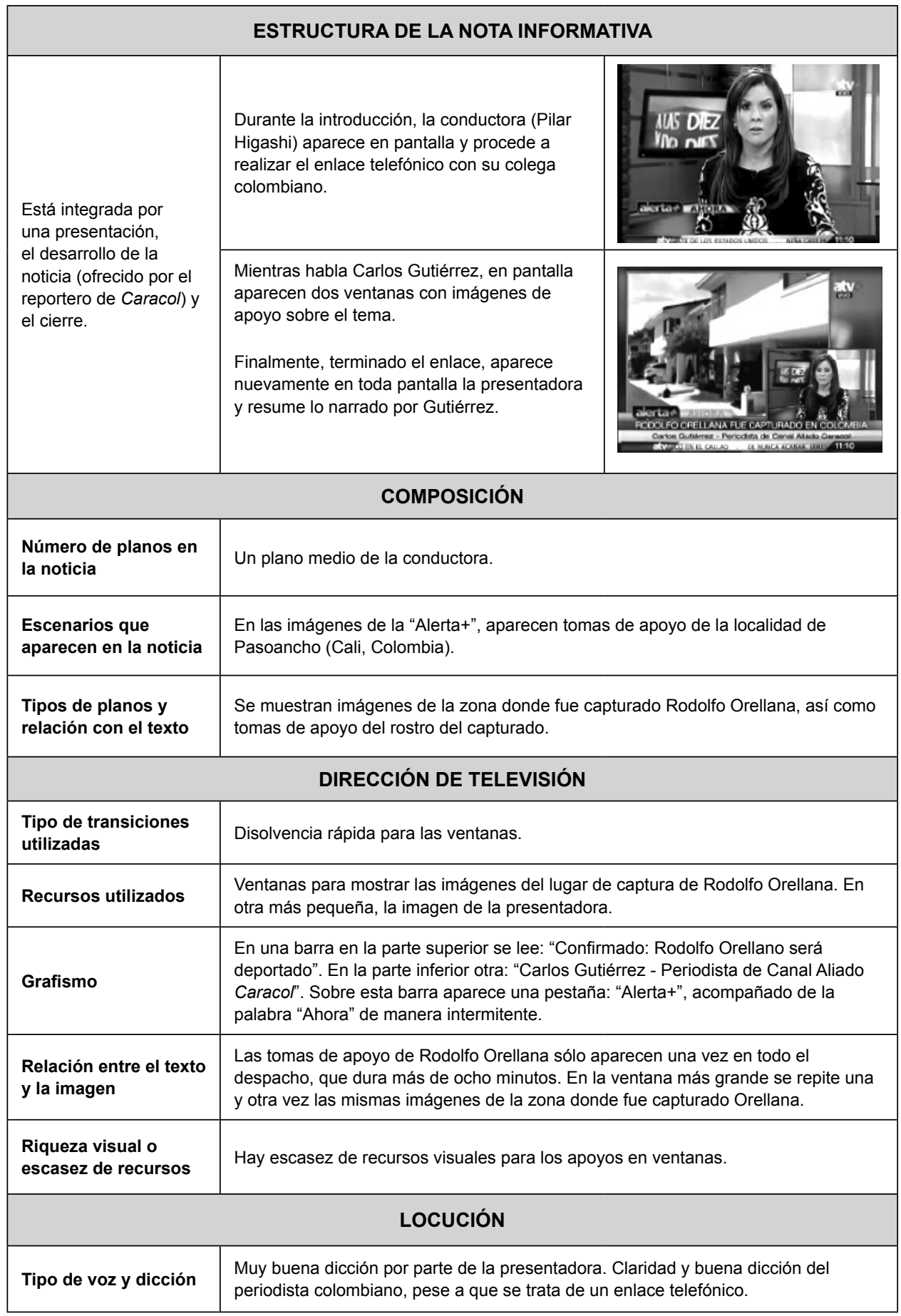




\begin{tabular}{|c|c|}
\hline $\begin{array}{l}\text { Ritmo y fluidez en la } \\
\text { locución }\end{array}$ & Fluido y fácil de entender. \\
\hline $\begin{array}{l}\text { Presencia del } \\
\text { periodista en cámara }\end{array}$ & La presentadora del programa aparece permanentemente en cámara. \\
\hline \multicolumn{2}{|r|}{ CONTENIDO } \\
\hline Fuentes utilizadas & $\begin{array}{l}\text { La fuente principal usada por } A T V+\text { es su colaborador en Colombia. Este cita } \\
\text { fuentes, como la Policía de su país, que confirmaron el diálogo entre los presidentes } \\
\text { Juan Manuel Santos y Ollanta Humala para acordar la expulsión de Orellana. }\end{array}$ \\
\hline Información ofrecida & $\begin{array}{l}\text { En este enlace, el periodista colombiano brinda información sobre la deportación de } \\
\text { Orellana y sus intenciones de ocultar su nacionalidad de origen. Además, confirma } \\
\text { la identidad del dueño de la casa en la que se escondía el prófugo peruano y otros } \\
\text { detalles sobre el operativo policial, su duración e integrantes. }\end{array}$ \\
\hline Enfoque adoptado & Informativo. \\
\hline
\end{tabular}

Fuente: Elaboración propia, basada en YouTube (2014c).

Figura 4: Análisis de noticia aparecida en TV Perú 7.3 y TV Perúl.

\begin{tabular}{|l|l|}
\hline \multicolumn{2}{|c|}{ DATOS GENERALES } \\
\hline $\begin{array}{l}\text { Fecha de emisión } \\
\text { del informativo }\end{array}$ & 18 de noviembre de 2014. \\
\hline Tema de la noticia & Congresistas piden investigar vínculos de Orellana con el APRA. \\
\hline
\end{tabular}

1 Noticia presentada en TV Perú 7.3 y TV Perú durante el noticiero matutino. Dicho espacio se transmitió en simultáneo en ambas señales. 


\begin{tabular}{|c|c|}
\hline $\begin{array}{l}\text { Escenarios que } \\
\text { aparecen en la } \\
\text { noticia }\end{array}$ & $\begin{array}{l}\text { Se presentan } 6 \text { escenarios, pero uno principal (el Congreso de la República). El resto } \\
\text { aparece en apoyos del Ministerio Público, de Colombia y Perú (en estos dos últimos con } \\
\text { imágenes de Rodolfo Orellana, su captura y traslado). }\end{array}$ \\
\hline $\begin{array}{l}\text { Tipos de planos } \\
\text { y relación con el } \\
\text { texto }\end{array}$ & $\begin{array}{l}\text { Predomina el plano busto. En los apoyos se identifican planos generales, medios, de } \\
\text { detalle, entre otros. }\end{array}$ \\
\hline \multicolumn{2}{|r|}{ EDICIÓN } \\
\hline $\begin{array}{l}\text { Tipo de } \\
\text { transiciones } \\
\text { utilizadas }\end{array}$ & Principalmente disolvencia (rápida) y corte. \\
\hline $\begin{array}{l}\text { Adecuación del } \\
\text { ritmo narrativo }\end{array}$ & Las imágenes sí van al ritmo del texto del periodista. \\
\hline $\begin{array}{l}\text { Uso del sonido } \\
\text { ambiente }\end{array}$ & $\begin{array}{l}\text { Hay sonidos ambientales, incluso debajo del audio del reportero. Se mantienen los } \\
\text { niveles correctos de audio. }\end{array}$ \\
\hline $\begin{array}{l}\text { Relación entre el } \\
\text { texto y la imagen }\end{array}$ & $\begin{array}{l}\text { En líneas generales, correcto, aunque algunas imágenes no tienen relación con el texto. } \\
\text { Por ejemplo, cuando se mencionan las "comisiones investigadoras", no se utiliza un } \\
\text { apoyo de alguna comisión parlamentaria, sino de Orellana detenido. }\end{array}$ \\
\hline $\begin{array}{l}\text { Riqueza visual } \\
\text { o escasez de } \\
\text { recursos }\end{array}$ & $\begin{array}{l}\text { Aparecen imágenes recientes (la captura de Orellana), pero hay escasez cuando se } \\
\text { refieren, por ejemplo a las "comisiones investigadoras", entre otros puntos. }\end{array}$ \\
\hline \multicolumn{2}{|r|}{ LOCUCIÓN } \\
\hline $\begin{array}{l}\text { Tipo de voz y } \\
\text { dicción }\end{array}$ & $\begin{array}{l}\text { Voz femenina. Predominio del registro central. Correcta dicción, pero al final de cada } \\
\text { frase o idea se arrastra la última sílaba, dándole un tono particular a su lectura. }\end{array}$ \\
\hline $\begin{array}{l}\text { Tiempo verbal } \\
\text { usado en la } \\
\text { narración }\end{array}$ & Uso del tiempo pasado. \\
\hline $\begin{array}{l}\text { Ritmo y fluidez en } \\
\text { la locución }\end{array}$ & Locución fluida y fácil de entender. \\
\hline $\begin{array}{l}\text { Presencia del } \\
\text { periodista en } \\
\text { cámara }\end{array}$ & La reportera no aparece en cámara. \\
\hline \multicolumn{2}{|r|}{ CONTENIDO } \\
\hline Fuentes utilizadas & Las fuentes principales son los congresistas. \\
\hline $\begin{array}{l}\text { Procedencia de } \\
\text { las imágenes }\end{array}$ & $\begin{array}{l}\text { Grabadas in situ (propias), archivo de la Policía de Colombia y de la semana anterior, } \\
\text { obtenidas por TV Perú. }\end{array}$ \\
\hline Enfoque adoptado & $\begin{array}{l}\text { El enfoque es principalmente informativo. No surgen valoraciones de la periodista, quien } \\
\text { sólo detalla lo que dijo cada uno de los congresistas mencionados en su nota. }\end{array}$ \\
\hline
\end{tabular}

Fuente: Elaboración propia, basada en YouTube (2014a). 
Figura 5: Análisis del bloque informativo del programa

"Mira Quién Habla" de Willax Televisión.

\begin{tabular}{|c|c|c|}
\hline \multicolumn{3}{|c|}{ DATOS GENERALES } \\
\hline $\begin{array}{l}\text { Fecha de emisión } \\
\text { del informativo }\end{array}$ & \multicolumn{2}{|l|}{13 de noviembre de 2014} \\
\hline Tema de la noticia & \multicolumn{2}{|l|}{ Capturan a Orellana en Cali. } \\
\hline Texto de la noticia & \multicolumn{2}{|c|}{$\begin{array}{l}\text { La noticia del día ha sido la captura del prófugo de la justicia Rodolfo Orellana, a } \\
\text { las 6:30 de la mañana en el exclusivo barrio El Ingenio de Cali, Colombia. La policía } \\
\text { colombiana señala que la captura de Orellana fue posible gracias a la colaboración de } \\
\text { Interpol, así como el cruce de información con la Policía y Fiscalía del Perú. Vamos a } \\
\text { ver un video del preciso momento en que la policía entra a la casa donde se escondía } \\
\text { Rodolfo Orellana y lo captura. } \\
\text { Luego de la captura de Rodolfo Orellana, el Ministro del Interior, Daniel Urresti, dio una } \\
\text { rueda de prensa. Ahí también dio detalles de la captura de la hermana de Orellana, } \\
\text { Ludith, en Huaral. Ella es considerada clave para el desmantelamiento de la red } \\
\text { Orellana. Escuchemos al ministro Urresti esta mañana en la sede de la Dirección } \\
\text { Antidrogas. } \\
\text { Esta tarde, por Twitter, el presidente de Colombia, Juan Manuel Santos, se refirió a } \\
\text { la captura de Rodolfo Orellana. Dijo que había hablado con el presidente Humala. } \\
\text { Además, dijo que el detenido sería entregado a las autoridades peruanas entre hoy } \\
\text { y mañana. Textualmente Santos dice: "Hablé con el presidente Ollanta Humala quien } \\
\text { agradece a Colombia, al General Palomino y a la Policía de Colombia por la captura de } \\
\text { Orellana". }\end{array}$} \\
\hline $\begin{array}{l}\text { Duración de la } \\
\text { noticia }\end{array}$ & 5' 11". & \\
\hline \multicolumn{3}{|c|}{ ESTRUCTURA DE LA NOTA INFORMATIVA } \\
\hline $\begin{array}{l}\text { Se comienza } \\
\text { con la entrevista } \\
\text { al congresista } \\
\text { Víctor Andrés } \\
\text { García Belaúnde } \\
\text { ( } 27 \text { minutos). El } \\
\text { segundo bloque es } \\
\text { el que se analiza } \\
\text { en esta tabla, }\end{array}$ & $\begin{array}{l}\text { En la primera parte, la presentadora, Gisú } \\
\text { Guerra, narra los detalles de la noticia y presenta } \\
\text { el video de la policía Colombiana referido al } \\
\text { operativo y posterior captura de Orellana. }\end{array}$ & \\
\hline $\begin{array}{l}\text { cuestiones } \\
\text { informativas la } \\
\text { detención del } \\
\text { prófugo peruano. } \\
\text { No se presentó } \\
\text { ningún informe al } \\
\text { respecto, sino se } \\
\text { decidió dividir el } \\
\text { tema en tres partes: }\end{array}$ & $\begin{array}{l}\text { Se presenta el soundbite del Ministro del Interior } \\
\text { sobre la captura de la hermana de Orellana. }\end{array}$ & 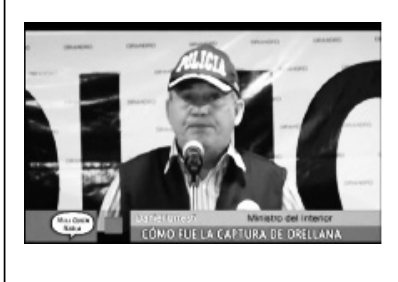 \\
\hline
\end{tabular}




\section{COMPOSICIÓN}

\begin{tabular}{|c|c|}
\hline \multicolumn{2}{|r|}{ COIMIPUSICIONN } \\
\hline $\begin{array}{l}\text { Número de planos } \\
\text { en la noticia }\end{array}$ & $\begin{array}{l}\text { Fundamentalmente el plano medio de la presentadora. A continuación, se presenta } \\
\text { el video de la captura de Orellana, con múltiples planos a lo largo del minuto y } 14 \\
\text { segundos de duración. El soundbite cuenta con un plano medio del Ministro del Interior. } \\
\text { Se recurre a una claqueta en pantalla con el tweet de Santos. }\end{array}$ \\
\hline $\begin{array}{l}\text { Escenarios que } \\
\text { aparecen en la } \\
\text { noticia }\end{array}$ & Si se engloba lo exhibido en el estudio y los que aparecen en las noticias, 3 . \\
\hline \multicolumn{2}{|r|}{ DIRECCIÓN DE TELEVISIÓN } \\
\hline $\begin{array}{l}\text { Tipo de } \\
\text { transiciones } \\
\text { utilizadas }\end{array}$ & Disolvencia de duración media. \\
\hline $\begin{array}{l}\text { Recursos } \\
\text { utilizados }\end{array}$ & $\begin{array}{l}\text { Gráficos en la pantalla de la escenografía virtual, así como barras con los siguientes } \\
\text { textos: "Capturan a Orellana en Cali", "Cómo fue la captura de Orellana" y "Santos habla } \\
\text { de captura de Orellana". }\end{array}$ \\
\hline $\begin{array}{l}\text { Relación entre el } \\
\text { texto y la imagen }\end{array}$ & $\begin{array}{l}\text { Sí hay relación permanente entre lo que se dice en texto (entradillas de la conductora) y } \\
\text { las imágenes proyectadas en el fondo. }\end{array}$ \\
\hline $\begin{array}{l}\text { Riqueza visual } \\
\text { o escasez de } \\
\text { recursos }\end{array}$ & Hay pocos videos para presentar, pero son bien aprovechados. \\
\hline \multicolumn{2}{|r|}{ LOCUCIÓN } \\
\hline $\begin{array}{l}\text { Tipo de voz y } \\
\text { dicción }\end{array}$ & Voz femenina. Correcta dicción. Se registra mínimos tropiezos en algunas partes. \\
\hline $\begin{array}{l}\text { Tiempo verbal } \\
\text { usado en la } \\
\text { narración }\end{array}$ & Al inicio se usan tiempos compuestos, pero también pasado perfecto. \\
\hline $\begin{array}{l}\text { Ritmo y fluidez en } \\
\text { la locución }\end{array}$ & Aunque pausada, resulta fluida. \\
\hline $\begin{array}{l}\text { Presencia del } \\
\text { periodista en } \\
\text { cámara }\end{array}$ & Sí. \\
\hline \multicolumn{2}{|r|}{ CONTENIDO } \\
\hline Fuentes utilizadas & $\begin{array}{l}\text { Tres fuentes principales: Policía colombiana, Ministro del Interior peruano y cuenta de } \\
\text { Twitter del presidente Juan Manuel Santos. }\end{array}$ \\
\hline Enfoque adoptado & Netamente informativo. \\
\hline
\end{tabular}

Fuente: Elaboración propia, basada en YouTube (2014c). 


\section{Analizando una denuncia}

Además del género informativo, también es importante analizar un reportaje, con alcances más interpretativos. Para ello, tomaremos como muestra uno de los más representativos desde que se comenzó con este estudio: la investigación sobre el resguardo policial a la casa de Óscar López Meneses, emitida por Willax Televisión en noviembre de 2013.

\section{a) Ficha técnica}

- Título: "Óscar López Meneses: el espía espiado".

- Cadena: Willax Televisión.

- Duración: 28’43" (solo el reportaje. Con presentación y conclusiones: 35 '43”).

- Tiempo de producción: cuatro meses y medio.

- Fecha de emisión: 13 de noviembre de 2013.

- Autora: Cecilia Valenzuela.

- Colaboradores para el reportaje: Óscar Quispe, Alejandra Fonseca, Omar Arbulú y Clarck Valentín.

- Programa: "Mira Quién Habla".

- Cortes publicitarios: Ninguno.

\section{b) Análisis de contenido}

- Tema: resguardo policial irregular en casa de Óscar López Meneses.

- Sinopsis: durante meses, Óscar López Meneses, ex operador del antiguo jefe de inteligencia nacional y hoy sentenciado Vladimiro Montesinos, contaba con un resguardo policial excesivo e irregular en su casa. ¿Por qué razón?, ¿qué vínculos tenía con la policía y el Gobierno? Estas son dudas que el reportaje plantea.

- Enfoque y tipo de reportaje: este reportaje está enfocado en mostrar la sospechosa presencia de diversas unidades de la Policía Nacional del Perú cerca de la casa de Óscar López Meneses y de su padre. Además se profundiza en López Meneses, sus allegados y los supuestos vínculos con personas ligadas al poder. Este es un reportaje de investigación y denuncia que se vale de recursos como entrevistas, la vigilancia periodística (en espacios públicos), imagen satelital, fotografías, archivo, entre otros.

- Contexto: este reportaje se realiza con la finalidad de denunciar vínculos entre jefes de la Policía Nacional del Perú y el ex operador montesinista Óscar López Meneses. Antes de la emisión, la directora del programa (Cecilia Valenzuela) detalló cómo recibió el dato preliminar de esa protección policial y la decisión de diseñar la investigación, debido a que consideró que dicha información era "tremendamente seria". Al final, Valenzuela también asegura que esta denuncia se hizo porque la población debe saber qué es lo que protegían las autoridades: si a López Meneses o una serie de actividades clandestinas.

- Fuentes empleadas: un antiguo oficial de la PNP fue la base para el reportaje. No tenía pruebas, "solo su palabra", como dijo Valenzuela; sin embargo, este dato sirvió para iniciar toda la investigación. Ya en el reportaje se mencionan fuentes policiales, sin detallar nombres; también, información de RENIEC, entrevistas con autoridades, policías implicados en el caso y otras personas. 
- Personajes que intervienen en cámara: la directora del programa, Cecilia Valenzuela, quien también ejerce de reportera y consulta directamente a los policías; habla a través del intercomunicador con alguien que está dentro de la casa de López Meneses y hace al menos tres stand-ups.

- Funciones del narrador: la narración, realizada por la misma Valenzuela, es casi como una conversación, por su manejo vocal.

- Papel del reportero: firme e incisivo al momento de hacer las preguntas a sus entrevistados (policías y autoridades al final del reportaje).

\section{c) Análisis de la estructura}

En el arranque de este reportaje aparecen imágenes tomadas por el servicio de Google Street que muestran los diversos vehículos policiales en la calle Batallón Libres de Trujillo (Santiago de Surco). Para ilustrar y hacer más claro el planteamiento del problema, Valenzuela asegura que una cantidad de seguridad similar es propia de un dignatario. Luego se ofrecen detalles del tiempo que el programa "Mira Quién Habla" estuvo siguiendo el caso, así como el número exacto de unidades desplegadas para el resguardo, bajo las órdenes del ex jefe de la Séptima Región Policial de Lima, Luis Praeli.

La reportera precisa que en esa casa vive alguien vinculado a la etapa más oscura del país. A continuación, señala a qué unidades de la Policía pertenece cada grupo enviado hasta la residencia y asegura que todos ellos resguardan la vivienda de Óscar López Meneses. Dicho esto, Valenzuela empieza a contar la cantidad real de efectivos y unidades en las inmediaciones de la casa. Luego, se dirige hasta el intercomunicador de la casa de López Meneses para hablar con él. Y deja todo en suspenso.

A partir del cuarto minuto, se presenta el perfil de Óscar López Meneses, así como los vínculos que tenía con el ex ministro fujimorista Víctor Malca Villanueva. Además, se presenta el caso del padre de López Meneses, quien también contaba con unidades policiales para el resguardo de su casa en Vista Alegre (Surco), con relevos cada ocho horas, en julio de 2013. Incluso en una parte del reportaje se le puede ver entregando comida a los agentes que lo protegían. Ya para noviembre de ese año, la seguridad aumentó e incluso había un portatropas que, según fuentes policiales no reveladas por la periodista, reflejaba una demostración de poder ante los miembros de las Fuerzas Armadas y la Policía Nacional.

Presentadas las pruebas visuales, se cita un archivo de "La Ventana Indiscreta", de abril de 2006, que ofrece más detalles sobre López Meneses. Entre estos, por ejemplo, que era uno de los hombres de confianza de Vladimiro Montesinos en la época fujimorista: un nexo entre los congresistas tránsfugas y el Servicio de Inteligencia Nacional de los noventas. Además, fue acusado de ocultar equipos de interceptación telefónica (“chuponeo") y se le incautaron armas. Con el uso de archivo, también se recuerda que, según Augusto Vega, López Meneses mantenía contacto desde prisión con el presidente Ollanta Humala, cuando este último era candidato presidencial en el 2006. 
Terminado el testimonio de archivo, reaparece en pantalla Valenzuela dirigiéndose al intercomunicador: se escucha una voz que replica y niega que López Meneses viva en el número marcado; la periodista va a interrogar a los policías que están custodiando en ese momento. Muchos responden a medias, prefieren no detallar más sobre su servicio, otros dicen que están dando seguridad al distrito y otros simplemente se niegan y suben la ventanilla del automóvil. Un policía da una pista y asegura que ellos, desde ahí, resguardan un puesto del Comando Conjunto de las Fuerzas Armadas (CCFFAA). Esto le sirve a la directora de "Mira Quién Habla" para comunicarse directamente con el asistente del Jefe del Comando Conjunto de las Fuerzas Armadas, quien asegura que su superior (el almirante José Cueto Aservi) no vive en esa dirección.

Al no encontrar una respuesta clara, la periodista realiza una llamada telefónica al entonces Ministro del Interior, Wilfredo Pedraza, y le pide explicaciones. Él dice que, formalmente, la Policía Nacional no da servicios de resguardo a López Meneses, pero que tendrá que investigar lo sucedido y comprobar lo que la periodista le ha contado. En su declaración, Pedraza también rechaza que alguien con los antecedentes de dicho personaje tenga relación con la Policía y que sea objeto de protección de esta institución. Finalmente, Valenzuela acude a Luis Praeli, ex jefe de la Séptima Región Policial de Lima, quien menciona que en diciembre de 2012 se recibió una orden de resguardo para esa dirección y él ingresa recién a la jefatura en marzo de 2013. Asegura que debieron haber verificado el servicio. Por otro lado, afirma que López Meneses no vive en esa casa, pero Valenzuela le refuta argumentando que lo han visto ellos mismos saliendo de dicha vivienda.

A continuación, la periodista presenta una prueba que vinculaba aún más a Praeli con López Meneses: la fotografía de una actividad oficial de la Séptima Región Policial de Lima, a la que fue invitado el cuestionado personaje. Informado sobre esto, el Ministro del Interior se indigna y dice que es una vergüenza lo que está pasando. Aprovecha la oportunidad también para afirmar que no tiene ningún tipo de relación con López Meneses.

El cierre del reportaje es breve. El periodista Clarck Valentín (quien estaba haciendo vigilancia con su videocámara cerca del Batallón Libres de Trujillo) es arrestado por el mismo coronel en jefe de la Unidad Policial de Emergencia. Valenzuela termina su informe: "El nerviosismo era total".

\section{d) Análisis de la forma}

Durante los casi 30 minutos de duración, el reportaje presenta múltiples elementos visuales y sonoros. Se aprovechan los sonidos ambientales en los momentos precisos del recorrido del equipo de "Mira Quién Habla" dentro de su vehículo. Cuenta con imágenes de Google Earth y Google Street, así como fotografías obtenidas por las propias fuentes del equipo de investigación de Willax TV. Para detallar quién era López Meneses (y Víctor Malca Villanueva) el programa utilizó imágenes de archivo.

En cuanto a los gráficos presentados, se recurrió a la RENIEC para mostrar las fotos de Malca Villanueva y del padre de Óscar López Meneses. En videographics está permanente 
el logo del programa y el título del reportaje (“López Meneses: El espía espiado”) escrito en altas. Las entrevistas telefónicas son acompañadas con una fotografía del personaje que habla en ese momento, así como sus créditos. En determinadas secuencias, el reportaje está musicalizado.

La edición es adecuada, guardando concordancia con la redacción. El estilo es explicativo y descriptivo. Sin embargo, se hubiera aprovechado en usar recursos como la fecha y hora de grabación sobre las imágenes de vigilancia periodística u otros elementos para que las comunicaciones telefónicas no aparezcan sólo con una imagen estática (fotografía). Como fuere, estos detalles no menoscaban el impacto de la denuncia.

\section{A modo de conclusión}

Si bien el grado de televidentes peruanos que consumen los canales de noticias no es masivo (comparado a los medios generalistas), quienes buscan estos espacios lo hacen por la oferta de su programación, así como por los enfoques y el tratamiento informativo presentado. En este punto, importa mucho el prestigio ganado por el canal, no sólo por estar siempre con "la primicia", sino principalmente por la responsabilidad asumida por sus directivos y periodistas. Esto es en la rigurosidad del trabajo, el respeto por los principios del medio y la escala de valores de la carrera. Podremos añadirle incluso aspectos importantes, tales como los recursos técnicos del medio y la propuesta gráfica y audiovisual.

Haciendo una sencilla comparación con sus pares extranjeros, podemos observar que muchos de los aspectos mencionados en el párrafo anterior no están plenamente desarrollados en los canales de noticias locales. Las razones son diversas: limitaciones en los recursos humanos, en las finanzas, en la logística o de otra índole. Pese a ello, lo más importante será formar una identidad propia y una reputación con lo que se dispone, dándole un sello de calidad a cada producción y no amparándose únicamente en el prestigio de la empresa operadora o el grupo matriz del canal de noticias.

Para lograr la excelencia también es importante la especialización de los periodistas y de los comunicadores sociales en general. Las universidades deben formar profesionales completos, disciplinados, respetuosos de los valores de esta carrera y siempre cercanos al arte y la cultura en todo sentido, enriqueciéndose aún más sus productos (ya sea en enfoque, redacción, postproducción y más). Profesionales que sean amantes del conocimiento en su forma más completa. En respuesta a dicha preparación (y al posterior resultado de cada profesional), las empresas deben garantizar adecuadas condiciones laborales para sus colaboradores.

\section{Fuentes consultadas}

Abril Vargas, N. (1999). Periodismo de opinión. Madrid: Síntesis. 
Al Rashed, A. (2014). “To Obama: Syria's moderate opposition is the only option”. Extraída el 29/VI/2014 desde http://english.alarabiya.net/en/views/news/middle-east/2014/06/25/ To-Obama-Syria-s-moderate-opposition-is-the-only-option.html

Bandrés, E. y otros (2000). El periodismo en la televisión digital. Barcelona: Paidós.

Bibb, P. (1997). Ted Turner: It Ain't as Easy as It Looks. Colorado: Johnson Books.

Canales, R. (2009). El servicio de noticias en el Perú. Lima: USMP.

\section{Cebrián, $M$.}

_(2004a). Modelos de televisión: generalista, temática y convergente con Internet. Barcelona: Paidós.

_(2004b). La información en televisión. Obsesión mercantil y política. Barcelona: Gedisa.

Cembrero, I. (2008, abril 27). "Televisión Al Jazeera, domesticada". Extraída el 16/ II/2014 desde http://elpais.com/diario/2008/04/27/radiotv/1209247201_850215.html

Clasesdeperiodismo.com (2012, diciembre 10). "No las uses: frases cliché de periodistas". Extraída el 20/V/2014 desde http://www.clasesdeperiodismo.com/2012/12/10/no-las-usesfrases-cliche-de-periodistas/

\section{CNN, canal de noticias.}

_(2011, febrero 19). "La cadena 'Al Jazeera' denuncia que Libia bloqueó su señal de noticias”. Extraída el 25/I/2014 desde http://mexico.cnn.com/mundo/2011/02/19/lacadena-al-jazeera-denuncia-que-libia-bloqueo-su-senal-de-noticias

_(1999). Manual de estilo y referencia de CNN en Español. Atlanta: CNN.

Coya, H. (2014). El periodista y la televisión. Los desafios de la prensa en la era de la alta definición. Lima: Fondo Editorial PUCP.

\section{El Comercio, portal web.}

_(2014, noviembre 13). “QQuién es Rodolfo Orellana? Así funcionaba su red delictiva”. Extraída el 24/XI/2014 desde http://elcomercio.pe/politica/justicia/quien-rodolfo-orellanaasi-funcionaba-su-red-delictiva-noticia-1771050

_(2013, noviembre 13). "Policía Nacional del Perú protege a un operador de Vladimiro Montesinos”. Extraída el 24/XI/2014 desde http://elcomercio.pe/politica/gobierno/policianacional-peru-protege-operador-vladimiro-montesinos-noticia-1658274

El Universal (2014, febrero 14). "Maduro: Sacar del aire a NTN24 fue una decisión de Estado". Extraída el 23/II/2014 desde http://www.eluniversal.com/nacional-ypolitica/140213/maduro-sacar-del-aire-a-ntn24-fue-una-decision-de-estado

Estremadoyro, J. (2003). Periodismo televisivo [volúmenes I y II]. Lima: Escuela de Periodismo Jaime Bausate y Meza. 
Hume, G. (2014, octubre 9). Director de Willax Televisión, ex editor general de Canal $N$. Entrevista personal. Lima.

Infobae (2014, febrero 20). "Maduro contra CNN: "Vamos a sacarlos de Venezuela", Extraída el 23/II/2014 desde http://www.infobae.com/2014/02/20/1545176-madurocontra-cnn-vamos-sacarlos-venezuela

La Nación (2008, enero 13). “Al Arabiya: una voz moderada en el mundo árabe”. Extraída el 10/VII/2014 desde http://www.lanacion.com.ar/978300-al-arabiya-una-voz-moderadaen-el-mundo-arabe

Marín, C. (2006). Periodismo audiovisual: información, entretenimiento y tecnologías multimedia. Barcelona: Gedisa.

Martín Vivaldi, G. (1993). Géneros periodísticos. Madrid: Paraninfo.

Martinchuck, E. y Mietta, D. (2002). Televisión para periodistas. Un enfoque práctico. Buenos Aires: La Crujía.

Mateu, M. (1998). "La entrevista en televisión”. En Balsebre, A.; Mateu, M. y Vidal, D. La entrevista en radio, televisión y prensa. Madrid: Cátedra.

\section{Moreno, $\mathbf{P}$.}

_(2003). "El periodismo informativo en televisión: lenguaje, género y estilo". Extraída el 17/ IV/2014 desde http://revistas.ucm.es/index.php/ESMP/article/view/ESMP0303110269A/1 2697

_(1998). Curso de redacción periodística en prensa, radio y televisión. Sevilla: Editorial MAD.

Ostrow, A. (2011, marzo 4). "What the Egyptian Revolution Taught Al Jazeera About Digital". Extraída el 25/I/2014 desde http://mashable.com/2011/03/05/al-jazeera-digital/

Patterson, C. (2003). "El buen reportaje, su estructura y características". Revista Latina de Comunicación Social, núm. 56. Extraída el 20/IV/2014 desde http://www.ull.es/publicaciones/latina/20035633patterson.htm

Perú 21 (2016, 18 julio). “Ollanta Humala: Escándalos, acusaciones, protestas y renuncias en su gestión”. Extraída el 20/VII/2016 desde http://peru21.pe/politica/ollanta-humalaescandalos-acusaciones-protestas-y-renuncias-durante-su-gestion-2252343

Ramonet, I. (1998). La tiranía de la comunicación. Madrid: Debate.

Rodero Antón, E. (2007). “Caracterización de una correcta locución informativa en los medios audiovisuales". Extraída el 23/V/2014 desde http://www.academia.edu/363016/Caracterizacion_de_una_correcta_locucion_ informativa_en_los_mensajes_audiovisuales 
Rodríguez, P. (1994). Periodismo de investigación. Técnicas y estrategias. Barcelona: Paidós.

\section{Russia Today, portal web.}

_(2012a, abril 3). "La cobertura objetiva del conflicto sirio no le interesa a Al-Jazeera". Extraída el 16/II/2014 desde http://actualidad.rt.com/actualidad/view/41291-La-coberturaobjetiva-del-conflicto-sirio-no-le-interesa-a-Al-Jazeera _(2012b, marzo 21) "Los medios también intervienen en el conflicto sirio". Extraída el 16/II/2014 desde http://actualidad.rt.com/actualidad/view/40751-Los-mediostambi\%C3\%A9n-intervienen-en-conflicto-sirio

Vargas, J. (2014, diciembre 5). Gerente de prensa de TV Perú (2012-2015). Entrevista personal. Lima.

Wikström, C. (2011, febrero 9). "Syria: “A kingdom of silence””. Extraída el 17/II/2014 desde http:/www.aljazeera.com/indepth/features/2011/02/201129103121562395.html

Yanes, R. (2002). "La noticia y la entrevista. Una aproximación a su concepto y estructura". Extraída el 21/IV/2014 desde http://grupo.us.es/grehcco/ambitos09-10/yanes.pdf

\section{YouTube, sitio web.}

_(2014a, noviembre 18). "Caso Orellana: congresistas de distintas bancadas piden investigar vínculos con el APRA” Extraída el 5/XII/2014 desde

https://www.youtube.com/watch?v=8RdU43Sv-tY

_(2014b, noviembre 13). "Mira Quién Habla - NOV 13 - Parte 2/8 - CAPTURAN A ORELLANA EN CALI". Extraída el 5/XII/2014 desde

https://www.youtube.com/watch?v=T8c5Zx6QyMw

_(2014c, noviembre 13). "CONFIRMADO: Rodolfo Orellana será deportado". Extraída el 5/XII/2014 desde https://www.youtube.com/watch?v=TwtsSNgAUbA

_(2014d, noviembre 13). "Rodolfo Orellana Rengifo capturado en Colombia 13-11-2014". Extraída el 5/XII/2014 desde https://www.youtube.com/watch?v=j4xDZAKBU38

_(2014f, noviembre 13). "Rodolfo Orellana Rengifo: Informe sobre la red del empresario recién capturado". Extraída el 5/XII/2014 desde https://www.youtube.com/watch?v=mHzF0YDUGo

_(2013a, noviembre 13). “Óscar López Meneses: el espía espiado (reportaje + editorial) parte 1". Extraída el 6/XII/2014 desde https://www.youtube.com/watch?v=iX-pJFS8yjM _(2013b, noviembre 13). “Óscar López Meneses: el espía espiado (reportaje + editorial) parte 2”. Extraída el 6/XII/2014 desde https://www.youtube.com/watch?v=nV4k28157OI (2013c, noviembre 13). "Óscar López Meneses: el espía espiado (reportaje + editorial) parte 3". Extraída el 6/XII/2014 desde https://www.youtube.com/watch?v=Rx6OWt19_j4 